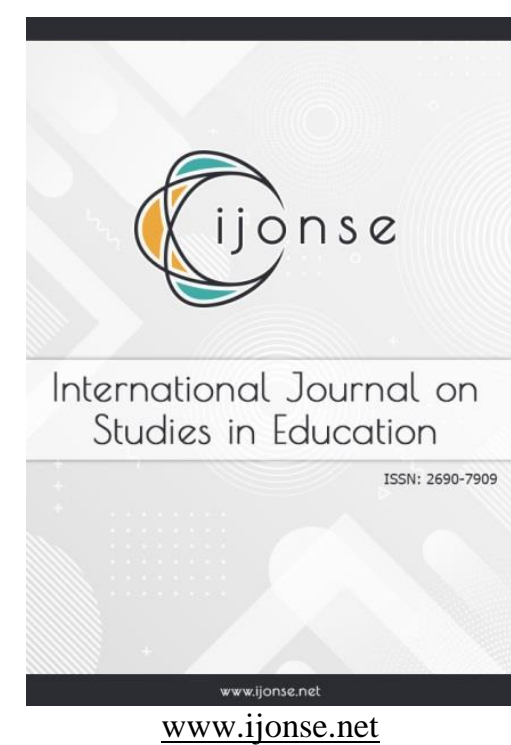

\title{
Cultural Influences on Early Intervention Services
}

Sultan Saeed Alzahrani

University of Jeddah, Saudi Arabia

Linda Flynn-Wilson

University of New Orleans, United States of America

$\underline{\text { www.ijonse.net }}$

\section{To cite this article:}

Alzahrani, S. S., \& Flynn-Wilson, L. (2021). Cultural influences on early intervention services. International Journal on Studies in Education (IJonSE), 3(1), 1-9.

International Journal on Studies in Education (IJonSE) is a peer-reviewed scholarly online journal. This article may be used for research, teaching, and private study purposes. Authors alone are responsible for the contents of their articles. The journal owns the copyright of the articles. The publisher shall not be liable for any loss, actions, claims, proceedings, demand, or costs or damages whatsoever or howsoever caused arising directly or indirectly in connection with or arising out of the use of the research material. All authors are requested to disclose any actual or potential conflict of interest including any financial, personal or other relationships with other people or organizations regarding the submitted work. 


\title{
Cultural Influences on Early Intervention Services
}

\author{
Sultan Saeed Alzahrani, Linda Flynn-Wilson
}

\begin{tabular}{|c|c|}
\hline Article Info & Abstract \\
\hline Article History & \multirow{9}{*}{$\begin{array}{l}\text { This survey-based, quantitative research investigated Early Intervention teachers' } \\
\text { perception about Early Intervention services in Mecca Region in The Kingdom } \\
\text { of Saudi Arabia. This research focused on the cultural influences in the provision } \\
\text { of services by professionals. Two options were offered to subjects to complete } \\
\text { the survey: 1) an online survey and 2) a hard copy of the survey which was } \\
\text { distributed to teachers in Early Intervention Centers. The majority of the } \\
\text { participants completed the online survey. Data was collected and analyzed. The } \\
\text { results showed that the teachers in Mecca Region in Saudi Arabia indicated that } \\
\text { they considered the culture of the children and families when determining } \\
\text { curriculum and services in their programs. }\end{array}$} \\
\hline $\begin{array}{l}\text { Received: } \\
27 \text { May } 2020\end{array}$ & \\
\hline Accepted: & \\
\hline 20 September 2020 & \\
\hline Keywords & \\
\hline Early Intervention & \\
\hline Special education & \\
\hline Early childhood & \\
\hline & \\
\hline
\end{tabular}

\section{Introduction}

Saudi Arabia is situated in the middle of three continents namely; Europe, Africa, and Asia. It holds the majority (80\%) of land in the Arabian Peninsula (Powers, Ramirez Redmond \& Elberg, 1966). The Saudi Arabia Kingdom is bordered by the Red Sea to the west; United Arab Emirates, Qatar and Arabia Gulf to the east; Kuwait, Iraq, and Jordan to the north; and Yemen and Omar to the south (Al-Hamli, 2008). Based on the recent statistics of the General Authority for Statistics in Saudi Arabia in 2017, it is comprised of 13 provinces and 33.7 million Saudi Arabian people, nearly 30\% were laborers with their families who came to the country from other countries to secure work. Religious beliefs or affiliations can vary for those who came to work in Saudi Arabia, but Islam is the official religion in the country (Arab Cultural Awareness, 2006). The primary language in Saudi Arabia is Arabic, but different dialects are noticeable (Nagata, 2014). As an example, people in the north of Saudi Arabia speak the Arabic language with different dialects than the people who live in the southern regions of Saudi Arabia. Because English is used as the standard language for all ethnicities, the English language is a second language in Saudi Arabia. Thus, residents of Saudi Arabia have their own unique cultures, beliefs, languages and backgrounds which influence the educational systems within the country of Saudi Arabia.

\section{Special Education in Saudi Arabia}

The diversity of languages and cultures in Saudi Arabia helped to establish international schools for various ethnic groups. In addition, the general educational programs, special education services, and the types of curriculum and instruction were influenced. Special education services were established in 1958 in Saudi Arabia (Al-Hamli, 2008) and are still in the early stages compared to western countries. Consequently, some issues exist in the delivery of special education services to students with disabilities from different races or those who do not speak Arabic or English. For example, not all children attend school when they have disabilities. Some families choose to keep their children at home due to societal expectations, cultural beliefs, and/or level of comfort with the available services. Special education services are improving on an ongoing basis as teachers and educational systems become knowledgeable about recommended practices with culturally, linguistically, and diverse children and families.

\section{Early Intervention in Saudi Arabia}

Even though special education services are improving, issues still exist with the delivery of Early Intervention (EI) services for young children with disabilities birth through age six and their families. One of the major concerns is the limited Early Intervention services available for children from birth-to-six with disabilities and their families in Saudi Arabia. In the 1980s, special education programs for young children were created 
(Khattab, 1995). Currently, there are three major cities in the western region of Saudi Arabia with five EI centers which include both center- and home-based service delivery models. Within these programs, education and therapy services are available as needed.

With limited EI services in Saudi Arabia, the challenges of delivering special education services to young children with disabilities and their families from different cultures or languages is a major concern. Much still needs to be accomplished to ensure that recommended practices are utilized in EI programs. Teachers need to be sensitive to the cultural, religious, ethnic, and linguistic differences of their students and families. The curriculum and instructional strategies must consider the diversity of their students as well as their disability needs.

\section{Education of EI Teachers in Saudi Arabia}

Individuals who graduate with a bachelor's degree in Saudi Arabia are trained in many different areas of special education including learning disabilities, autism, blindness, deafness, intellectual disability, multiple disabilities, orthopedic challenges, speech and language disorders, and motor delays (Al-Hamli, 2008). However, they are required to choose an area of specialization. Qualifications to work in Special Education, as well as Early Intervention, include a bachelor's degree, a diploma, or a master's degree. No special certification or degree exists for EI.

Another option for teaching young children with disabilities in Saudi Arabia is a one-year diploma. To instruct young children (3-6 years old), teachers are required to have a four-year professional undergraduate degree in special education as described previously or obtain a one-year diploma if the bachelor's degree is not in special education. In Saudi Arabia, a master's degree is optional, but a bachelor's degree and/or a master's degree is required to teach in classrooms for children with disabilities. The master's program in special education involves either disability-specific or general special education (Alamri, 2011). Also, advanced instruction and training for special educators is offered in the master's degree and aligns individuals' coursework with employment choices. Since EI is so new in Saudi Arabia, universities have just begun to add birth-to-six special education as an area of study. Currently, no students have graduated from a bachelor's or master's degree program in Early Intervention.

\section{Teachers, Families and Cultures}

All families have cultural values that influence their own personal belief and behaviors. Differences in perspectives and beliefs may occur among people assumed to have the same culture (Flynn-Wilson, French, \& Buswell, 2000). These differences in cultures may affect the educational system and how teachers and families interact with one another. When educators understand the cultural influences on the teaching and learning of children with special needs, they are better able to facilitate collaboration between school and home (García \& Ortiz, 2006). Also, teachers should incorporate the values of families into their curricula so that a cultural mismatch does not occur which could make it more difficult to effectively collaborate.

Lamorey \& Suzanne (2002) established that EI requires active collaboration among parents, medical care staff, and society to facilitate the social-cultural development of young children with disabilities. The types of educational early childhood programs that children attend may be related to their race and culture. For example, in Saudi Arabia, it is essential that there is agreement in religious and social beliefs between school and home. Parents in Saudi Arabia try to send their children to programs that value the same culture and beliefs that they do. Without agreement, conflict in beliefs and cultures could lead to less successful EI services. It may also result in fewer parents' participation in the EI program.

It is important for educators to receive both pre- and in-service training to ensure they are culturally competent. The findings of a study conducted by Xu \& Drame (2008) supported the importance of cultures and beliefs in Early Intervention programs. They found that educators who were not aware of cultural differences found it difficult to provide appropriate services and supports to diverse students who struggled behaviorally and academically. If professional development opportunities for teachers are limited, they may not have adequate preparation to implement effective practices for socially, linguistically and culturally diverse students (García \& Ortiz, 2006). 


\section{Purpose of the Study}

The goal of this study was to examine cultural influences on the Early Intervention services in the western region of Saudi Arabia. This study surveyed teachers in five EI centers to discover the training completed, educational level, specialization, and influence of culture on Early Intervention services for young children with disabilities.

\section{Method}

Limited research exists about the perspectives of teachers related to the type and quality of EI services in Saudi Arabia. This study investigated the effect of culture on EI services from the teachers' perspective via a survey.

\section{Participants}

Participants were recruited from three major cities (Jeddah, Mecca, and Taif) in the western region of Saudi Arabia. Criterion for participation was an individual who teachers in one of the five Early Intervention centers for young children from birth to six years old with disabilities and their families. A total of fifty-two participants were recruited. Sampling is the process of selecting a suitable representative sample from a given population. A representative sample was utilized with teachers who volunteered to participate. They were asked to complete a survey that included basic demographic information and questions related to culture and teaching. The fifty-two participants were ensured that all information was confidential and would only be used for research purposes.

\section{Survey Content and Process}

This study used a researcher-designed survey to gather data. The content of the survey included questions related to demographics of the participants as well as statements related to culture. The items were created through a review of the literature, Early Intervention recommended practices, and the personal experiences of the researchers. A Likert scale was used in the survey for this study. The subjects chose their responses to statements utilizing the following Likert scale: never (0), rarely (1), frequently (2) and always (3). Many researchers utilize this method in their studies due to its simplicity, stability, and ability to show the degree of perspective of a person (Bryman, 2003).

For the purpose of this study, the survey was divided into two components. One section included demographic data and the other included statements related to cultural practices in the classroom. Teachers' demographic information included gender, age, city of employment, years of teaching experience, level of education and where the degree was earned, and area of specialization. The other section included four statements related to classroom cultural practices: (1) I select teaching materials that are relevant to Saudi culture (examples: dolls, books, clothing, cooking utensils, household articles, furniture); (2) I received training during or after my teaching career in how to be competent with students who are socially, linguistically, and culturally diverse; (3) I include culturally-relevant practices into how I teach (examples: prayer, wodoa, values, stories); and (4) I modify my curriculum to ensure that the cultural and religious values of families are included in my teaching. When educators understand the cultural influences of their teaching of children with disabilities, they are better able to address learning needs of the students as well as facilitate collaboration between school and home (García \& Ortiz, 2006).

For this study, an online survey was created using survey monkey. This study was conducted in an Arabic community, and thus, the surveys were translated from English to Arabic before being distributed. The translation was completed by a reputable translation agency in Jeddah city. Once the translation was completed, the researchers and a Saudi Arabia colleague reviewed the survey to ensure that the content about disability was accurate. The survey was simple, straight-forward, and brief to facilitate the respondents' willingness to respond (Al-Hamli,2008). Then, the translated surveys were sent to the Early Intervention teachers in the five EI centers to begin the data collection process. The survey was sent to the participants in two ways. First, an online link was sent to EI teachers via email. Second, the survey was given to the participants in person by a special education teacher in Jeddah city, if they preferred this mode of responding. For the purpose of obtaining a maximum number of participants, the researcher sent a follow-up email two weeks after the original survey was sent to potential subjects, reminding them to complete the survey. For those individuals who were approached face-to-face, the researchers sent a follow-up email reminding them to complete the survey. 


\section{Data Analysis Procedures}

The data received from the surveys was analyzed using a variety of statistical analyses relevant to the study. Statistical Package for Social Sciences (SPSS) software was used to code the data. The investigators used descriptive statistics and analysis of variance (ANOVA) to determine the differences between the independent variables (gender, teaching experience, and the level of education) and the dependent variables (the cultural influences on the Early Intervention services in the western region of Saudi Arabia). Analysis of variance (ANOVA) is used to show the differences between the mean of the variables (Tabachnick, \& Fidell, 2007).

Also, ANOVA can be computed to determine the differences between two variables within a small sample size. ANOVA was tabulated to (or "intending to") determine if there existed significant variances in teaching staff's' perception of the Early Intervention services. The statistical significant difference was calculated at <.05 (2-tail test). For this study, the measure of standard deviation, mean, and analysis of variance (ANOVA) was tabulated to measure the perception of the Early Intervention teachers towards Early Intervention services in the western region of Saudi Arabia.

\section{Results}

The goal of this study was to examine the backgrounds of teachers and cultural influences on the Early Intervention services in western Saudi Arabia. Initially, descriptive statistics were calculated to characterize the subjects. In total, there were fifty-two responses to the survey. However, one person did not declare his or her age and another person did not report the city in which he or she lived. Table 1 summarizes the demographic characteristics of the sample.

Table 1. Sample Demographics

\begin{tabular}{|c|c|c|}
\hline Variable & $\mathbf{n}$ & $\%^{a}$ \\
\hline \multicolumn{3}{|c|}{ Gender $n=52$} \\
\hline Male & 16 & $30.8 \%$ \\
\hline Female & 36 & $69.2 \%$ \\
\hline \multicolumn{3}{|c|}{ Age, $n=51$} \\
\hline Less than 30 years & 17 & $33.3 \%$ \\
\hline $31-40$ years & 25 & $49.0 \%$ \\
\hline $41-50$ years & 9 & $17.7 \%$ \\
\hline \multicolumn{3}{|c|}{ City where work, $n=51$} \\
\hline Jeddah & 19 & $37.3 \%$ \\
\hline Mecca & 19 & $37.3 \%$ \\
\hline Taif & 13 & $25.4 \%$ \\
\hline \multicolumn{3}{|c|}{ Educational level, $\mathrm{n}=52$} \\
\hline 1-yr diploma & 3 & $5.8 \%$ \\
\hline Bachelor's degree & 34 & $65.4 \%$ \\
\hline Graduate & 15 & $28.8 \%$ \\
\hline \multicolumn{3}{|c|}{ Specialization, $\mathrm{n}=52$} \\
\hline Special education & 37 & $71.1 \%$ \\
\hline General education & 15 & $28.9 \%$ \\
\hline \multicolumn{3}{|c|}{ Experience, $\mathrm{n}=52$} \\
\hline Less than 1 year & 7 & $13.5 \%$ \\
\hline $1-5$ years & 19 & $36.5 \%$ \\
\hline $6-10$ years & 20 & $38.5 \%$ \\
\hline More than 10 years & 6 & $11.5 \%$ \\
\hline \multicolumn{3}{|c|}{ Attended training program after joining EI program, $n=52$} \\
\hline Yes & 11 & $21.2 \%$ \\
\hline No & 41 & $78.8 \%$ \\
\hline \multicolumn{3}{|c|}{ Country where received university training, $\mathrm{n}=52$} \\
\hline Saudi Arabia & 39 & $85.0 \%$ \\
\hline Egypt & 4 & $7.7 \%$ \\
\hline Jordan & 9 & $17.3 \%$ \\
\hline
\end{tabular}


The majority of participants $(69.2 \%)$ were female. With respect to age, the highest percentage was between 31 and 40 years old $(49.0 \%)$, followed by those who are less than 30 years old $(33.3 \%)$. The smallest group consisted of participants 41-50 years old (17.7\%). None of the respondents were over 50 years old. With respect to the city in which they worked, participants were quite evenly distributed; $(n=19 ; 37.3 \%)$ worked in Jeddah, and another $(n=19 ; 37.3 \%)$ in Mecca and the smallest parentage worked in Taif $(n=13 ; 25.4 \%)$. The majority of the participants held a Bachelor's degrees $(n=34 ; 65.4 \%)$. Since individuals in Saudi Arabia must have a bachelor's degree in order to earn the 1-year certificate, for analysis purposes, the researchers combined the 1year certificate holders with the Bachelor's degree holders. The majority received their university training in Saudi Arabia $(n=39 ; 85.0 \%)$ while others were trained in either Jordan or Egypt. The majority of participants $(n=37 ; 71.1 \%)$ indicated that their specialization was special education; the remainder specialized in general education. About the same percentages had $1-5$ years of experience $(n=19 ; 36.5 \%)$ or $6-10$ years of experience $(n=20 ; 38.5 \%)$. Despite being a relatively experienced sample, a large majority of participants $(n=41 ; 78.8 \%)$ indicated that they had not received specialized training since they joined the EI program.

\section{Descriptive Statistics}

The survey instrument utilized four items to collected data on one variable which is cultural influences related to the provision of EI services. Descriptive statistics for each of these variables were used, including the response scale, the total score calculation, the possible score range, the actual score range, and the mean score for the scale. Table 2 summarizes the variable descriptive statistics.

Table 2. Dependent Variable Descriptive Statistics, $\mathrm{n}=52$

\begin{tabular}{lrrrrr}
\hline Scale & $\boldsymbol{M}$ & SD & Med & Min & Max \\
\hline Culture influence & 8.0 & 1.6 & 8.0 & 4.0 & 12.0 \\
\hline
\end{tabular}

Culture influence. Items 1-4 asked respondents about the influence of Saudi Arabian cultural beliefs on the delivery of the curriculum and instruction for young children with disabilities. The response scale for each item was: $0=$ never, $1=$ rarely, $2=$ frequently, and $3=$ always. The researchers calculated a total cultural influence score by summing the responses of items 1-4 with a possible score range of 0 to 12 . Among this sample, the mean score was $8.0(\mathrm{SD}=1.6)$. Thus, mean overall response is 2 (score of 8 divided by 4 items), indicating that participants tended to answer "frequently" to the cultural influence items.

\section{Assumptions}

To analyze data, the researchers conducted analysis of variance (ANOVA) tests. This type of test is founded on several statistical assumptions about the dataset. Therefore, before conducting analysis, the researchers tested for the accuracy of the assumptions. The first assumption was that there were no outliers. By generating boxplots, the researchers were able to determine whether there were any outliers for each survey scale (see Dawson, 2011). There were no outliers for any of the scales (see Figure 1), as demonstrated by the absence of data points outside the boxplot range. Therefore, the assumption of no outliers was supported.

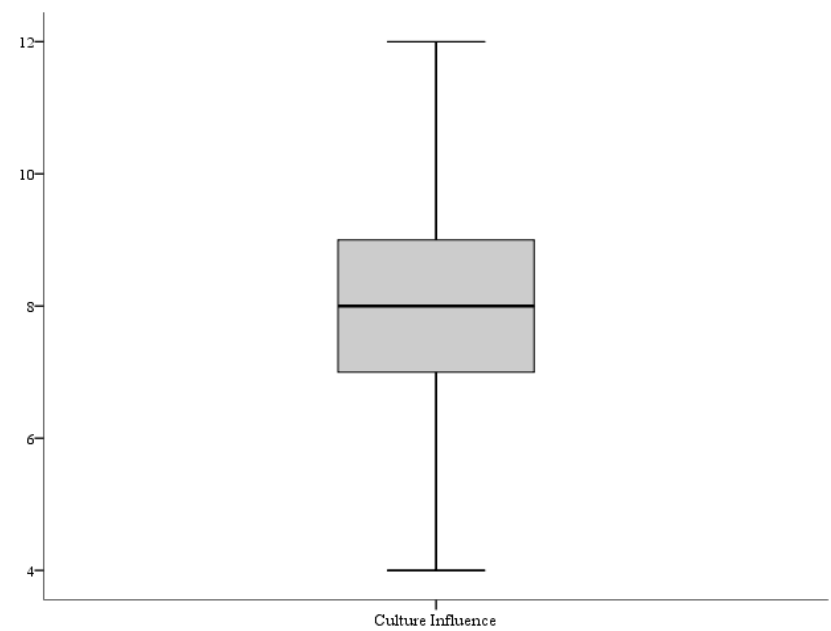

Figure 1. Boxplots of the Survey Scales to Demonstrate Lack of Outliers 
The section assumption for ANOVA is that the dataset is normally distributed. To test for normality, the researchers used the skewness statistic. If the statistic has an absolute value less than 1 , the distribution is considered to be approximately normal. All the variables' skewness statistics were within the range for normality (see Table 3). Therefore, the assumption of approximate normality is supported for all survey scales.

Table 3. Skewness and Kurtosis for the Total Forgiveness Scales, $\mathrm{n}=52$

\begin{tabular}{lcc}
\hline Variable & Skewness & Kurtosis \\
\hline Cultural influence & -.137 & .412 \\
\hline
\end{tabular}

The ANOVA test assumes that independent variables have equal variances. The researcher used Levine's test to test this assumption. The null hypothesis for this test was that the variances are equal for the groups. The $p$ values were less than .05 when testing inequality of variance in several scenarios. Variances were unequal among training history with respect to cultural influence, and among experience levels with respect to cultural influence. Table 4 summarizes this result.

Table 4. Tests for Equal Variances for the Survey Scales, $n=52$

\begin{tabular}{lccc}
\hline Variable & & Levine & $\boldsymbol{p}$ \\
\hline Cultural influence & Gender & .615 & .436 \\
Cultural influence & Training & .618 & .063 \\
Cultural influence & Specialization & .380 & .541 \\
Cultural influence & Experience & 3.029 & .038 \\
Cultural influence & Education & .809 & .439 \\
\hline
\end{tabular}

Because the $p$ value was greater than .05 , in some scenarios, the researchers had to reject the null hypothesis for two of the three scales, indicating that the variances were not equal for the independent variable groups for all the survey scales. For the three scales with unequal variances (cultural influence by experience), the researchers opted to use the Welch test instead of ANOVA. The Welch test is applicable when the assumption of homogeneity of variances is not supported. The hypothesis that culture makes a difference in the curriculum and instruction utilized was tested. To test the hypothesis, the researchers used ANOVA to determine whether there were differences in cultural influence due to the independent variables. The dependent variable was cultural influence, as measured by the survey instrument. The independent variables were gender (male, female), training (yes, no), specialization (general education, special education), experience (less than one year, 1-5 years, 6-10 years, more than 10 years), and education (Bachelor's degree, graduate degree). Table 5 summarizes the results. The following paragraphs contain a detailed description of results for each independent variable.

Table 5. ANOVA Results and Descriptive Statistics for the Cultural Influence, $n=52$

\begin{tabular}{|c|c|c|c|c|c|c|}
\hline Variable $^{\mathrm{a}}$ & & & & & $F$ & $p$ \\
\hline Gender & Male & Female & & & .09 & .768 \\
\hline $\bar{n}$ & 16 & 36 & & & & \\
\hline$M(S D)$ & $8.1(1.4)^{\mathrm{a}}$ & $7.9(1.7)$ & & & & \\
\hline Training & Yes & No & & & .09 & .769 \\
\hline$n$ & 11 & 41 & & & & \\
\hline$M(S D)$ & $8.1(2.3)$ & $7.9(1.4)$ & & & & \\
\hline Specialization & General Ed & Special Ed & & & .69 & .409 \\
\hline$n$ & 15 & 37 & & & & \\
\hline$M(S D)$ & $7.7(1.6)$ & $8.1(1.6)$ & & & & \\
\hline Education & Bachelors & Graduate & & & 1.49 & .229 \\
\hline $\bar{n}$ & 37 & 15 & & & & \\
\hline$M(S D)$ & $8.1(1.6)$ & $7.5(1.7)$ & & & & \\
\hline Experience & $<1 \mathrm{yr}$ & $1-5 \mathrm{yrs}$ & $6-10 \mathrm{yrs}$ & $>10$ yes & $2.68^{\mathrm{a}}$ & .087 \\
\hline$n$ & 7 & 19 & 20 & 6 & & \\
\hline$M(S D)$ & $7.7(2.6)$ & $7.9(1.6)$ & $7.9(1.1)$ & $8.7(2.0)$ & & \\
\hline
\end{tabular}

${ }^{a}$ Welch statistic used in lieu of ANOVA because the assumption of homogeneity of variance was not supported $* p<.05 ; * *<.01$ 
Gender. There was no significant difference between the genders with respect to cultural influence $(\mathrm{F}[1,50]=$ $.09, p=.768$ ). Both the males and females scored about 8.0 on the cultural influence scale. The average response for both males and females was 2 , or frequently. This indicates that both males and females viewed cultural differences has having an impact on EI.

Training. As with gender, there was no difference with respect to cultural influence when comparing teachers who had received training since entering the EI program with those who had not $(\mathrm{F}[1,50]=.09 ; p=.769)$. Those who received training and those who did not receive training all scored about 8.0 on the cultural influence scale. The average response for both groups was 2 , or frequently.

Specialization. Again, there was no significant difference between specializations $(\mathrm{F}[1,50]=.69 ; p=.409)$. Those whose specialization was general education did not differ in their mean scores for cultural influence. Both groups scored around 8 . The average response for both groups would be 2 , or frequently.

Education. The difference was not significant between Bachelor's degree and graduate degree holders (F $[1,50]$ $=1.49 ; p=.229)$. Those whose educational level was Bachelor's degree did not differ in their mean scores for cultural influence from those who hold graduate degrees. Both groups scored around 8 . The average response for both groups would be 2 , or frequently.

Experience. Because the Levine test revealed that the variances among the four age groups were not equal, the researchers used the Welch statistic to test for differences among the experience groups. The result was significant at the .10 level $(\mathrm{F}[3,48]=2.68 ; p=.087)$. The three less experienced groups had means between 7.7 and 7.9. The average responses for these groups was about 1.9, or between rarely and frequently. The group with more experience (more than 10 years) had a higher mean of 8.7. The average response for this group was 2.2 or between frequently and always. This indicates that, compared with less experienced teachers, more experienced were more likely to modify their EI instruction and services on the basis of cultural differences.

The majority of the variables showed that culture frequently influenced decisions made related to teaching young children with disabilities and their families. For gender, training, specialization, and education, the average response for all groups was above 2 (frequently), indicating that, on average, the participants rated culture as having frequent influence on Early Intervention services. The only difference observed was with respect to experience, where more experienced teachers reported a greater influence of culture on their instruction.

\section{Discussion}

Turning to the research question which focused on the extent to which, in participants' perception, culture influenced EI services for young children with disabilities, the findings of this study confirm the conclusion that culture does indeed influence EI services. This supports a previous finding (García \& Ortiz, 2006). In addition, $\mathrm{Xu}$ and Drame (2008) found that educators provided more appropriate services and supports to diverse students when they had more awareness of cultural differences. Also, the cultural fit of the children and families living in the same community assists in the creation of positive relationships between the school and home as well as impacts the EI services. A recent study (Loughlin, Bucci, Brooks, \& Berry, 2020) described the importance of a strong relationship between families and Early Intervention staff to impact the services provided.

The extent to which EI teachers in Saudi Arabia modify their EI services based on cultural differences has received little previous research attention. In the present study, all teachers reported making modifications based on cultural differences. This finding is promising for the current and future delivery of EI services. Interestingly, more experienced teachers proved more likely to make such modifications. Established teachers have a wealth of experience to "fall back on" and a level of confidence that newer teachers may not have. Similar results were found by Srihari and Kane (2020) who indicated that new teachers lacked experience working in the field of EI. However, additional research is needed to investigate this concept as well as the delivery of EI services in Saudi Arabia.

\section{Limitations of the Study}

This research investigated the cultural influences on the Early Intervention services in three cities, Jeddah, Mecca, and Taif, in Saudi Arabia. Thus, the findings of this study may not be similar to those of teachers in 
other regions who work with young children with disabilities. Therefore, the results obtained from the survey may not apply to other countries.

Only four cultural questions were asked in this study. Additional questions would have provided more information and guidance related to the influence of culture on teaching. Additionally, limited data was collected due to the newness of birth-to-six centers in Saudi Arabia which limited the number of subjects potentially available.

\section{Conclusion}

Using a survey design, the researchers gathered data on cultural influences on the Early Intervention services in the western province of Saudi Arabia. The results showed that EI teachers frequently alter their curricula and methods based on cultural differences. The results indicated that more experienced teachers were more likely to adapt their curricula to the cultural differences of their students. This finding points to the need for continued training to increase the number of qualified and experienced teachers working with young children with disabilities.

Despite a growing body of research supporting EI services for children with disabilities, such services have been slow to spread in Saudi Arabia (Al-Mousa, 2007; Alharbi, \& Tamim Al-Dar, 2013). While EI is growing in popularity, researchers still know too little about how teachers are providing services and what might be obstacles to effective EI instruction. Additional research will be required to confirm the findings of this study and to expand the understanding of EI teachers' methods and cultural decisions related to instruction.

Continued research will be needed to fill a gap in the literature and to provide guidance to administrators and teachers in Saudi Arabia and other countries of the Middle East. As EI continues to gain traction in Saudi Arabia, it is important to bear in mind that each student is an individual with individualized needs. The more we can empower teachers, through specialized training and experiences related to recommended practices to meet individual students' needs, the better the outcomes of EI are likely to be.

\section{References}

Alamri, M. (2011). Higher education in Saudi Arabia. Journal of Higher Education Theory and Practice, 11(4), 88.

Al-Hamli A. (2008). Investigation of special education teachers' attitudes towards education of pupils with special needs in Riyadh city in the Kingdom of Saudi Arabia. Masaryk University.

Alharbi, M. \&Tamim AL-Dar, N. (2013). The experience of Al-own center in the Early Intervention Services for children from birth to three year.

Al-Mousa, N. A. (2007). The Kingdom of Saudi Arabia experience in mainstreaming children with special educational needs in public schools.

Awareness, A. C. (58). Factsheets.(2006)."Tradoc Dcs Int”, Handbook No. 2. Fort Leavenworth: Office of The Deputy Chief of Staff.

Bryman, A. (2003). Research methods and organization studies (Vol. 20). Routledge.

Cagney, T. L. (2009). Attitudes of general education teachers toward including students with special needs. (Unpublished master thesis, Iowa State University).

Dawson, R. (2011). How significant is a boxplot outlier? Journal of Statistics Education, 19(2), 1-12.

Flynn-Wilson, LL, French, N., \& Buswell, B. (2000). Involving Families in School. In D. Sands, E, Kozleski, \& N. French (Eds.), Inclusive Education for the Twenty-First Century. Atlanta: Wadsworth Publishing Co, 75-112.

García, S. B., \& Ortiz, A. A. (2006). Preventing disproportionate representation: Culturally and linguistically responsive prereferral interventions. Teaching Exceptional Children, 38(4), 64.

Khattab, M. S. (1995). A comprehensive review of the status of early childhood development in the Middle East and North Africa. UNICEF.

Lamorey, S. (2002). The effects of culture on special education services: Evil eyes, prayer meetings, and IEPs. Teaching Exceptional Children, 34(5), 67.

Merza, H., (2012). The Saudi Early Intervention Services: Current Challenges and The Vision for Revision": Advances in Research and Praxis in Special Education in Africa, Caribbean and the Middle East, Sixth Book in the Series, Research on Education in Africa, the Caribbean and the Middle East. Info Age Publishing. 
Nagata, K. K. (2014). The scale of attitudes towards disabled persons (SADP): Cross-cultural validation in a middle income Arab country, Jordan. Review of Disability Studies: An International Journal, 3(4).

Powers, R. W., Ramirez, L. F., Redmond, C. D., \& Elberg, E. L. (1966). Geology of the Arabian Peninsula. Geological survey professional paper, 560, 1-147.

Tabachnick, B. G., \& Fidell, L. S. (2007). Experimental designs using ANOVA. Thomson/Brooks/Cole.

$\mathrm{Xu}$, Y., \&Drame, E. (2008). Culturally appropriate context: Unlocking the potential of response to intervention for English language learners. Early Childhood Education Journal, 35(4), 305-311.

\begin{tabular}{ll}
\hline & Author Information \\
\hline Sultan Saeed Alzahrani & Linda Flynn-Wilson \\
(D) https://orcid.org/0000-0002-2197-335X & (D) https://orcid.org/0000-0002-7461-1555 \\
University of Jeddah & University of New Orleans \\
Saudi Arabia & United States of America \\
Contact e-mail: ssaalhariri@uj.edu.sa & \\
\hline
\end{tabular}

